\title{
TRÊS TRADIÇÕES EXPLICATIVAS NA LEI DA QUEDA DOS CORPOS
}

\author{
Carlos Arthur Ribeiro do NASCIMENTO*
}

\begin{abstract}
RESUMO: O presente trabalho tenta mostrar como na justificação teórica do estudo do movimento naturalmente acelerado nos Discursos, Galileu combinaria três posturas metodológicas não perfeitamente coincidentes. Seriam elas: a demonstração ex hypothesi da tradição astronômica, inter pretada realistamente; a demonstração necessária da tradição aristotélico-euclidiana; a demonstração típica das "ciências intermediárias". Assim, mesmo a última obra de Galileu estaria longe de ser inequívoca em matéria de metodologia científica.
\end{abstract}

UNITERMOS: Galileu; Discursos; movimento naturalmente acelerado; raciocínio ex hyp othesi; Aristóteles; Euclides; ciências intermediárias; ótica.

Muito se tem discutido sobre as concepções científicas e metodológicas de Galileu. Talvez boa parte dos desacordos provenha de dois fatores. O primeiro seria a intenção de ler Galileu retrospectivamente, isto é, a intenção de descobrir nele os germes do que vai ser a ciência posteriormente. Dito melhor: lê-lo a partir de um estágio posterior da ciência. O segundo seria a pretensão de atribuir a Galileu uma coerência irrefragável, seja dentro da mesma obra, seja ao longo de sua extensa produção intelectual.

Propomo-no neste trabalho, seguir um caminho inverso. Quer dizer, em primeiro lugar, ler Galileu prospectivamente, isto é, a partir do que ele podia conhecer, tentando ele, eventualmente, ultrapassar o que podia conhecer. Além disso, lê-lo sem supor que seja sempre coerente, mesmo na mesma obra e na mesma passagem de tal obra. Parece-nos que esta postura consegue dar conta razoavelmente de certas dificuldades ou ambiguidades encontradas nos Discursos. Com efeito, encontrar-se-iam aproxi- madas nestas diferentes tradições de pensamento sem que se possa dizer que a síntese destas seja perfeita ou sem percalços.

1. O raciocínio ex hypothesi - $1{ }^{a}$ tradição

Comecemos com uma citação, maiṣ ou menos longa, dọs Discursos:

"Os acidentes que cabem ao movimento igual foram considerados no livro precedente. Resta tratar do movimento acelerado.

Em primeiro lugar convém investigar e explicar a definição que lhe caiba exatamente enquanto se encontra na natureza. Pois, embora não haja inconveniente em imaginar arbitrariamente alguma espécie de movimento e examinar as propriedades que dela decorrem - assim, com efeito, procedem os que se imaginam linhas helicoidais ou concóides resultantes de certos movimentos, embora estes não se encontrem na natureza e, louvavelmente, demonstraram hipoteticamente as propriedades de tais

* Departamento de Filosofia - Faculdade de Comunicação e Filosofia - Pontifícia Universidade Católica - 01000 São Paulo - SP. 
linhas - no entanto, visto que se encontra na natureza uma certa espécie de aceleração dos graves que caem, deci. dimos refletir sobre as propriedades destes na suposição de que a definição que daremos de nosso movimento acelerado venha a concordar com a essência dos movimentos naturalmente acelerados. O que confiamos ter, enfim, conseguido depois de repetidos esforços mentais, baseados principalmente na seguinte razão: que as propriedades sucessivamente demonstradas por nós aparecem como correspondentes ao que os experimentos naturais apresentam aos sentindos e congruentes com isto" (11, V.8, p. 197; 21, p. 145-146).

Convenhamos em denominar segunda parte desta passagem a que se inicia com as palavras "no entanto, visto que se encontra na natureza...” até o final da citação. Ela contém uma afirmação que nos traz imediatamente ao pensamento o método corrente da hipótese-dedução-experimento. Com efeito, Galileu diz que supõe que sua definição do movimento acelerado concorda com a essência dos movimentos naturalmente acelerados pelo fato de que "as propriedades sucessivamente demonstradas por nós aparecem como correspondentes ao que os experimentos naturais apresentam aos sentidos e congruentes com isto".

Sem dúvida, Galileu conhecia um aversão antiga e medieval desta forma de raciocínio que era denominada de modo geral raciocínio ex hypothesi. Era ela corrente em astronomia e foi sintetizada por Geminos (séc. I a.C.), sendo este reproduzido por Simplício (527-565) e, através deste último, passou à idade média. Tomás de Aquino, por exemplo, numa passagem frequentemente citada, resume esta longa tradição:

"De duplo modo podemos dar a razão de uma coisa. De um modo, para lhe provar suficientemente o fundamento; assim, nas ciências da natureza damos a razão suficiente para provar que o movimento do céu é sempre de velocidade uniforme. De outro modo, damos, não a razão que lhe prove suficientemente o fundamento, mas a explicativa da congruência desse fundamento já estabelecido, com os efeitos dele resultantes. Assim, na astronomia estabelece-se a razão dos excêntricos e dos epiciclos pelo fato de que, admitindo esse fundamento, podem-se salvar as aparências sensíveis a respeito dos movimentos celestes, sem ser contudo essa razão suficientemente probante; pois, talvez admitida outra suposição, as referidas aparências se pudessem salvar" (1, I. parte, q. 32, a. 1. , ad $2 \mathrm{~m})^{*}$.

Como o próprio Tomás de Aquino indica no texto que acabamos de citar, o raciocínio ex hypothesi não é uma prova em sentido absoluto. Ele estabelece apenas a congruência entre as conseqüências (empiricamente verificadas) e o fundamento suposto. Não o caráter absoluto deste último. Talvez com outras suposições se pudesse estabelecer também as mesmas conclusões. Quer dizer, Tomás de Aquino da do raciocínio ex hypothesi, como era de costume, uma interpretação operacional ou instrumentalista. Os excêntricos e epiciclos não correspondem a nada na realidade. São apenas artifícios ou regras que nos permitem relacionar dados de observação.

É aqui que incidiria uma profunda discordância de Galileu. Este se recusa a dar dos excêntricos e epiciclos ou, de maneira mais geral, das hypotheses uma interpretação meramente operacional ou instrumental. O raciocínio ex hypothesi é capaz de revelar a estrutura real do mundo. Eis uma passagem típica desta interpretação galileana:

"É preciso ainda prestar atenção que, em se tratando da mobilidade ou do repouso da terra e do sol, encontramosnos diante de um dilema de proposições contraditórias, das quais uma é neces-

* Utilizamos a tradução de A. Correia (7) ligeiramente modificada. O texto de Simplício acha-se reproduzido por P. Duhem (8, p. 9-11). 
sariamente verdadeira e que não podemos de maneira nenhuma chegar a dizer que, talvez, nem um nem outro caso se dê. Se, pois, a imobilidade da terra e o movimento do sol são verdadeiros de facto e a proposição contrária absurda, como sustentar razoavelmente que a proposição errônea concorda melhor com as aparências perceptíveis, quanto ao movimento e à disposição das estrelas, que a posição verdadeira? Quem não sabe que, na natureza, todas as verdades tomadas em conjunto formam um todo harmonioso ao passo que uma dissonância estrondosa se manifesta entre as hipóteses falsas e os efeitos verdadeiros? Veríamos, assim, concordar, em todos os pontos, a mobilidade da terra e a imobilidade do sol com a disposição de todos os corpos do mundo e com todas as observações feitas de maneira mais precisa por nós mesmos e nossos predecessores e, tal posição seria falsa? A imobilidade da terra e o movimento do sol, tidos como verdadeiros, não concordariam, pois, em caso nenhum com as outras verdades? Se pudessemos dizer que nem uma nem outra destas opiniões é verdadeira, poderia acontecer, sem dúvida, que uma fosse mais conveniente do que a outra para dar conta das aparências. Mas, que venhamos a afirmar que, destas duas posições, das quais uma é necessariamente verdadeira e a outra falsa, esta última corresponde melhor aos efeitos naturais, eis aí o que verdadeiramente ultrapassa minha imaginação. Acrescento, pois, e respondo: já que Copérnico reconhece ter satisfeito plenamente às exigências dos astrônomos com a hipótese comum, tida como ver- dadeira, como se dá que tenha querido ou podido satisfazer de novo às mesmas exigências como uma hipótese errônea e estúpida?”*

Cremos que é nesta perspectiva que seria preciso compreender o texto inicialmente citado dos Discursos. Por que Galileu não se contenta com um tratado meramente geométrico à moda dos gregos?** Por que quer ele ir além da geometria e falar de física? Falar de "uma certa espécie de aceleração dos graves que caem" que "se encontra na natureza"? Porque acredita que o raciocínio ex hypothesi pode revelar a estrutura do real e não se reduz a um simples artifício de cálculo.

A primeira tradição explicativa presente no trecho quje inicia o estudo do movimento uniformente acelerado na terceira jornada dos Discursos nos revelaria então uma interpretação realista do raciocínio ex hypothesi por parte de Galileu***.

\section{A tradição aristotélico-euclidiana}

Ao final da exposição citada no ińıcio deste trabalho, Galileu parece assaltado por certas dúvidas. Pelo menos crê necessário acrescentar outra justificativa à precedente. Eis o texto:

"Finalmente, na investigação dos movimentos naturalmente acelerados, como que nos conduziu pela mão a advertência do costume e do instituto da própria natureza em todas as suas demais obras, no exercício das quais costuma usar dos meios mais próximos, mais simples e mais fáceis. Penso, com efeito, que não há ninguém que creia que o nado e o vôo pode ser executado de modo mais simples e fácil do que

* Este trechoé tirado de um texto publicado por A. Favaro (11, V. 5, p. 351-363) sob o título Considerações sobre a opinião copernicana. Citamos de acordo com a tradução francesa de M. Clavelin (5, p. 140). Para o que se refere mais especificamente aos excêntricos e epiciclos, ver M. Clavelin (5, p. 142).

** A menção das linhas helicoidais é uma alusão ao Tratado das espirais de Arquimedes.

*** Esta afirmação concorda com as grandes linhas da análise de K. Popper (23) e de W.A. Wallace (26). Não pretendemos discutir o detalhe das propostas de Popper e Wallace. Digamos, no entanto, que Popper parece primeiramente interessado em expor o seu próprio pensamento. Galileu comparece apenas como ilustração. Por outro lado, concordamos plenamente com Wallace, cujo trabalho é de intenção predominantemente histórica, no que se refere ao caráter necessário e realista da ciência galileana. Não diríamos o mesmo no que diz respeito à hipótese de que Galileu utilizaria um raciocínio ex-suppositione distinto do ex hypothesi. Ver também de W.A. Wallace (27) e (28). 
aquele mesmo que é usado, por instinto natural, pelos peixes e pelas aves.

Então, pois, quando me dou conta de que uma pedra, que cai de uma altura a partir do repouso, adquire sucessivamente novos incrementos de velocidade, por que não crerei que tais aditamentos se dão pela razão mais simpl

examinarmos atentamente isto, não encontraremos aditamento ou incremento mais simples do que o que acrescenta sempre do mesmo modo. O que entendemos facilmente examinando a afinidade máxima do tempo e do movimento, pois, assim como a igualdade e uniformidade do movimento se define e concebe-se pelas igualdades dos tempos e dos espaços - denominamos então, assim, um movimento igual, quando espaços iguais são completados em tempos iguais - igualmente podemos perceber os incrementos de celeridade como feitos simplesmente através das igualdades das partes do tempo, concebendo na nossa mente que um movimento é uniformemente e do mesmo modo acelerado quando, em quaisquer tempos iguais, lhe são acrescentados aditamentos iguais de celeridade. ... E, assim, não parece de modo nenhum disonante da reta razão se consideramos que a intensificação da velocidade se dá segundo a extensão do tempo. Daí, a definição do movimento do qual iremos tratar pode ser considerada a seguinte: denomino movimento igualmente ou uniformemente acelerado aquele que, partindo do repouso, acrescenta a si, durante tempos iguais, momentos iguais de celeridade". (11, V.8. p. 197-198; 21, p.146).

aristotelıco-euclidıana de que a ciência parte de principios evidentes por si mesmos. Daí procurar apresentar sua definição (fí- sica) do movimento uniformemente acelerado como se dando "pela razão mais simples e mais óbvia a todos". Neste caso, à definição do movimento uniformemente acelerado não seria confirmada retrodutivamente pela congruência das propriedades deduzidas com as experimentadas. Ela é um princípio primeiro evidente por si mesmo, sendo esta evidência o sustentáculo de todo o arcabouço de propriedades deduzidas.

É claro, podemos relembrar as dificuldades encontradas pelo próprio Galileu. A definição do movimento uniformemente acelerado apresentada nos Discursos é resultado de um longo debate intelectual. Ele, aliás, o diz: "o que confiamos ter, enfim conseguido depois de repetidos esforços mentais....' É sabido como, de início, Galileu definiu erroneamente o movimento uniformemente acelerado supondo que os aumentos de velocidade se davam em função do espaço e não do tempo (15). Portanto, a definição do movimento uniformemente acelerado não seria "dada pela razão mais simples e mais óbvia a todos”.

A distinção escolástica entre princípios evidentes por si mesmos para todos e princípios evidentes por si mesmos pará os entendidos (1, I. parte, q. 2., a. 1. ) poderia salvar a afirmação galileana. A "razão mais simples e mais óbvia a todos" deveria ser compreendida com uma qualificação, quer dizer: a todos os entendidos. Esta distinção apresenta um certo paralelo com a distinção aristotélica entre axiomas e teses e tal classificação dos primeiros princípios, por Aristóteles, talvez nos ajude a compreender a pretensão de Galileu no trecho dos Discursos que estamos analisando.

Partamos de uma passagem dos Segundos Analíticos (2, Liv. I, 10, 76a31-77a4)*. Esta pode ser esquematizada da seguinte maneira:

* A ser comparada com uma outra (2, Liv. I, 2, 72a14-24). 


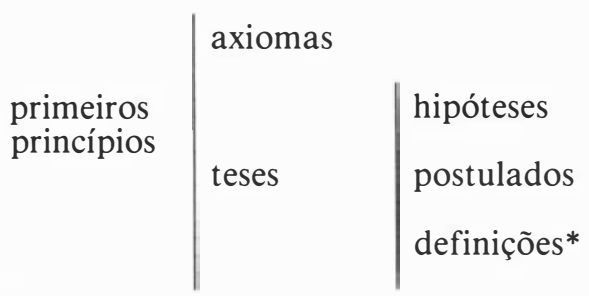

Evidentemente, Galileu não pretende que sua definição do movimento uniformemente acelerado seja um axioma, pois estes são princípios comuns a todos os setores do saber. Ela deve, pois, entrar no grupo das teses, que são princípios próprios a uma determinada ciência. Não pode ser tomada como um postulado, pois estes são postos ou afirmados sem ou contra a opinião de outrem. Restam as hipóteses e as definições. As primeiras afirma

e as segundas uma signıfıcaçao. Ora, Galileu está, na passagem em questão dos Discursos, afirmando uma significação (a do movimento uniformemente acelerado). Temos, pois, uma definição. Mas Galileu a pretende "real", isto é, trata-se da definição de algo que existe na natureza e não apenas da definição de um mero conteúdo de pensamento, da explicação do significado de um termo (definição nominal). Se aceitarmos a interpretação de S. Mansion de que Aristóteles acaba reduzindo os princípios próprios às definições reais $(18, \mathrm{p}$. 149-159 e p. 202-212)**, teremos talvez atingido uma compreensão melhor do que Galileu quereria dizer.

\section{Tradição das ciências intermediárias}

Esta terceira tradição aparece justamente na famosa passagem dos Discursos onde se.relata a experiência com o plano inclinado, que confirmaria experimentalmente a lei dos quadrados dos tempos. Transcrevamos o trecho que nos interessa diretamente:

"Simplício. Eu verdadeiramente tíve mais satisfação neste discurso simples e claro do Sr. Sagredo do que na, para mim obscura, demonstração do Autor; de tal maneira que fico bem convencido de que a coisa deve suceder deste modo, uma vez posta e aceita a definição do movimento uniformemente acelerado. Mas que esta seja a aceleração da qual se serve a natureza no movimento dos seus graves cadentes, eu ainda estou duvidoso; e por isso, para minha compreensão e de outros semelhantes a mim, parece-me que teria sido oportuno apresentar neste lugar alguma experiência daquelas que se disse que há muitas e que em diversos casos concordam com as conclusões demonstradas.

Salviati. Vós, como verdadeiro cientista, fazeis um pedido muito razóavel; e assim se costuma e convém nas ciências que aplicam às conclusões naturais as demonstrações matemáticas como se vê com os óticos, os astrônomos, os mecânicos, os acústicos e outros quais confirmam com experiências sensíveis os seus princípios que são os fundamentos de toda a estrutura subsequente. Por isso, não desejo que nos pareça supérfluo se com excessiva delonga discorramos sobre este primeiro e máximo fundamento, sobre o qual se apoia a imensa máquina de infinitas conclusões das quais somente uma pequena parte foi colocada neste livro pelo Autor, o qual terá feito bastante para abrir a entrada e a porta que estava até agora fechada aos intelectos especulativos. A respeito, portanto, das experiências, o Autor não descurou de fazê-las; e, para assegurar-se de que a aceleração dos graves que caem naturalmente varia na proporção supra-mencionada, muitas vezes me encontrei eu, na sua companhia a fazer prova disto, da maneira seguinte"(11, Vol.8, p. 212).

* Para o estabelecimento deste quadro inspiramo-nos das indicações de A. Correia (6), especificamente (6, p. 28). Ver também Th. L. Heath (13, p. 117-124).

** Ver especialmente (18, p. 206-212). Conferir também (18, p. 213-217 e p. 254-274). 
Salviati dá a definição técnica das ciências intermediárias - "ciências que aplicam às conclusões naturais as demonstrações matemáticas" - e enumera os exemplos mais conhecidos*. É de ressaltar que coloque em primeiro lugar na lista, a ótica. Com efeito, talvez seja neste setor que mais se praticou o que ele diz: confirmar com experiências sensíveis os princípios que fundamentam toda a estrutura subseqüente.

Alguns dados históricos podem apoiar este recurso sobretudo à ótica. Euclides escreveu uma Ótica que tem uma estrutura semelhante à dos Elementos. Começa ela por sete "definições" que são, de fato, postulados. Seguem-se 58 teoremas que dizem respeito a questões elementares de perspectiva. Aparentemente não há nenhum recurso à experiência para fundamentar os postulados**. No entanto, encontramos tal recurso no prefácio da Revisão da Ótica de Euclides feita por Theon de Alexandria (fim do sec. IV d.C.). Neste prefácio, Theon aduz certos dados de experiência para apoiar a primeira definição (postulado) da Otica de Euclides tal como formulada por ele Theon***. Algo de semelhante pode também ser encontrado na Ótica de Ptolomeu (séc. II d.C.). No início do livro III desta obra, Ptolomeu propõe três princípios básicos para a ciência dos espelhos (catótrica) e procura fundamentá-los experimentalmente. Chega mesmo a utilizar um aparelho para verificar a lei de reflexão (o ângulo de incidência é igual ao ângulo de reflexão), o tcrceiro destes princípios $* * * *$. Alhazen (Ibn al-Haytham, 962-1038 d.C.) no seu Optice Thesaurus (Kitab al-
Manazir), livro IV, cap. III descreve minuciosamente a construção de um aparelho para testar a lei de reflexão*****. Rogério Bacon colocará no De Multiplicatione Specierum este tipo de experiência acima da demonstração (ratio) e da prova através do efeito, pois ela nos faz ver diretamente como a natureza opera ${ }^{* * * * * *}$.

Poderíamos e, até mesmo deveríamos continuar este percurso até a época de Galileu*******. O que dissemos nos parece, no entanto, suficiente para apontar a corrente de pensamento em que Galileu se situa na página dos Discursos citada ao início da terceira seção deste nosso trabalho.

O curioso é que ficamos aqui diante de uma alternativa.

a) A lei dos quadrados dos tempos não é mais considerada como uma propriedade do movimento uniformemente acelerado tal como era apresentada no texto de abertura do estudo deste movimento na terceira jornada dos Discursos, tanto na perspectiva da demonstração ex hypothesi como na da tradição aristotélico-euclidiana. Encontramos talvez ainda esta postura nas palavras de Simplício que aludiriam a este contexto. A lei dos quadrados dos tempos seria agora, nas palavras de Salviati, o "primeiro e máximo fundamento". b) O "primeiro e máximo fundamento" seria a definição do movimento uniformemente acelerado. Mas então a experiência do plano inclinado não a verifica diretamente. Revertemos à primeira tradição, isto é, à demons-

* Ver a respeito J. Gagné (10) e nosso ensaio (19), especialmente (19, p. 36-47).

** O texto grego da Ótica de Euclides, acompanhado de uma tradução latina, foi publicado por J.L. Heiberg (14). Há tradução francesa (9) e inglesa (4). A Ótica de Euclides foi conhecida no oaidente desde pelo menos o sec. XIII. A histórica das traduções latinas é mais ou menos complicada. Ver a respeito W.R. Theisen (25).

*** Para o texto da Revisão de Theon, ver J.L. Heiberg (14).

**** A Ótica de Ptolomeu foi traduzida para o latim por Eugênio de Palermo no séc. XII. Esta tradução foi publicada por G. Govi (12) e, numa edição crítica por A. Lejeune (16).

***** O tratado de Alhazen foi traduzido para o latim no fim do séc. XII ou início do XIII. Esta tradução foi editada r'or F. Risner, Basileia, 1572. Há uma reimpressão da edição de Risner feita por D.C. Lindberg (17).

****** O De Multiplicatione Specierum foi editado por J.H. Bridges em apêndice à sua edição do Opus Majus (3). Para uma análise do De Multiplicatione, permitimo-nos remeter a nossa tese de doutorado (20), especialmente, no que toca ao tópico aqui mencionado (20, p. 91-99). Para uma informação geral sobre o De Multiplicatione ver nosso artigo (22).

******* Para alguns dados rápidos acerca desta tradição após o séc. XIII, ver G. Sarton (24, o. 88-94). 
tração ex hypothesi interpretada realistamente por Galileu.

Em conclusão podemos dizer que indubitavelmente Galileu se guiava por um ideal científico que pretendia demonstrações necessárias que dissessem respeito às coisas do mundo extramental em si mesmas. Ele está longe do convencionalismo. Mas como justificar em teoria tal postura? Eis aí onde Galileu of erece mais matéria para ambiguidades do que, para decisões claras e inequívocas. Sua última obra, os Discursos, testemunharia as ambiguidades teóricas em que Galileu esteve envolvido até o final de sua carreira científica.

\section{AGRADECIMENTOS}

Agradeço a Jézio Hernani Gutierre, João de Fernandes Teixeira, José Oscar de Almeida Marques, Marcos Barbosa de Oliveira e Maria Eunice Quilici Gonzales uma discussão prévia deste trabalho.

NASCIMENTO, C.A.R. do - Three explanatory traditions in the Law of Falling Bodies.Trans/Form/Ação São Paulo, 6: 5-12, 1983.

ABSTRACT: This paper tries to show how in the theoretical justification of the study of naturally accelerated motion in the Discourses, Galileo would have combined three not perfectly identical methodological attitudes. Those attitudes would be: the ex-hypothesi demonstration from the astronomical tradition, realistically interpreted; the necessary demonstration from the Aristotelian and Euclidean tradition; the typical demonstration of the "mixed sciences". Thus, even Galileo's last work would be far from unequivocal

KEY-WORDS: Galileo; Discourses; naturally accelerated motion; ex hypothesi reasoning; Aristotle; Euclid; mixed sciences; optics.

\section{REFERÊNCIAS BIBLIOGRÁFICAS}

1. AQUINO, T. de - Summa theologiae. Roma, Ed. Paulinae, 1966.

2. ARISTÓTELES - Segundos analíticos. In: Obras. Trad. por Francisco de P. Samaranch - Madrid, Aguilar, 1969.

3. BACON, R. - Opus majus. Unveränderter Nachdruck. Frankfurt/Main, Minerva G.m.b.H.,1964.

4. BURTON, E. - The optics of Euclid. The Journal of the Optical Society of America (35): 357-372, 1945.

5. CLAVELIN, M. - Galilée et le refus de l'équivalence des hypothèses. In: Galilée. Aspects de sa vie et de son oeuvre. Paris, P.U.F., 1968. p.127-152.

6. CORREIA, A. - Noção de análise e de hipótese na filosofia de Aristóteles. Revista da $\mathrm{Fa}$ culdade de Filosofia e Letras de São Bento (4): 15-40, 1931.

7. CORREIA, A. - Suma teológica de S. Tomás de Aquino. São Paulo, Faculdade de Filosofia "Sedes Sapientiae", 1946.

8. DUHEM, P. - Sózein tà phainómena, Essai sur la notion de théorie physique de Platon à $\mathrm{Ga}$ lilée. Paris, Herman, 1908.
9. EECKE, P. Ver. - Euclide, l'optique et la catoptrique. Paris, Librarie Scientifique et Technique. Albert Blanchard, 1959.

10. GAGNÉ, J. - Du quadrivium aux scienciae mediae. In: Arts libéraux et philosophie au Moyen Âge (Actes du IV $V^{\mathrm{e}}$ congrès international de philosophie médiévale). Montréal, Inst. d'Etudes Méd., Paris, Vrin, 1968. p. 975-986.

11. GALILEI, G. - Le opore di Galileo Galilei. Edizione nazionale a cura di A. Favaro. 2.ed. Florença, G. Barbéra, 1929-1939. v. 1-20.

12. GOVI, G. - L'Ottica di Claudio Tolomeo. Turim, Paravia, 1885.

13. HEATH, T. L. - The thirteen books of Euclid's Elements. New York, Dover, 1956. v.1.

14. HEIBERG, J. L. - Euclidis optica, Opticorum recensio Theonis, Catoptrica, Cum scholiis antiquis. In: - Euclidis opera omnia. Leipzig, Teubner, 1895 . v.7.

15. KOYRÉ, A. - La loi de la chute des corps (Descartes et Galilée). In: - Etudes galiléenes. Paris, Hermann, 1966. p.83-158.

16. LEJEUNE, A. - L'Optique de Claude Ptolémée. Louvain, Publ. Univ. de Louvain, 1956. 
São Paulo, 6: 5-12, 1983.

17. LINDBERG, D. C. - Opticae thesaurus. New York, Johnson Reprint, 1972.

18. MANSION, S - Le jugement d'existence chez Aristote. Ed. de l'Institut Superieur de Phiolosophie de Louvain. Paris, Vrin, 1946.

19. NASCIMENTO, C.A.R. do - Le statu épistémologique des "sciences intermédiaires" selon S. Thomas d'Aquin. Cahiers d'Etudes Médiévales, 2 (La science de la nature: théories et pratiques). Montréal, Bellarmin, Paris, Vrin, 1974.

20. NASCIMENTO, C.A.R. do - Une théorie des opérations naturelles fondés sur l'optique: Le De multiplicatione specierum de Roger Bacon. Montreal, Univ. de Montreal, 1975. (Tese-Doutorado).

21. NASCIMENTO, C.A.R. do - Quatro textos de Galileu. Trans/Form/Ação, 3: 143-7, 1980.

22. NASCIMENTO, C.A.R. do - Une théorie des opérations naturelles fondée sur l'optique: Le De multiplicatione specierum de Roger Bacon. Manuscrito (5): 32-55, 1981.
23. POPPER, K . - Três concepções do conhecimento humano. In: - Os pensadores. S. Paulo, Abril, 1975, v.44, p. 385-409.

24. SARTON, G. - Seis alas. Buenos Aires, Eudeba, 1965.

25. THEISEN, W.R. - The medieval tradition of Euclid's optics. s. l. Univ. Wisconsin, 1972. (Unpublished Doctoral Dissertation).

26. WALLACE, W.A. - Galileo and Reasoning Ex Suppositione: The Methodology of the Two New Sciences. Boston Studies in the Philosophy of Science (32): 79-104, 1974.

27. WALLACE, W.A. - Galileo and the Thomists. In: St. Thomas Aquinas, 1274-1974, Commemoratives Studies. Toronto, Pontifical Institute of Mediaeval Studies, 1974. v.2, p. 293-330.

28. WALLACE, W.A. - Galileo Galilei and the Doctores parisienses. In: - New Perspectives on Galileo. Dordrecht, Bọston, D. Reidel, 1978. p. 87-138. 